\title{
Re-design of decorative pattern of Kirgiz nationality
}

\author{
Fang Liu ${ }^{1,}$, Wei Peng ${ }^{2, b}$ \\ ${ }^{1}$ School of Humanities \& Arts,Chongqing University of Science \& Technology, \\ Chongqing,401331, China; \\ ${ }^{2}$ School of Design, Sichuan Fine Arts Institute, Chongqing ,401331, China. \\ aliufangsunny721@126.com, bvweil@foxmail.com
}

Keywords:Kirgiz; decorative patterns; re-design

\begin{abstract}
This paper extracts patterns and colors which the locals like most, and integrates recycling, with Kirgiz pattern in culture as the core, through field research and data analysis, what's more, it seeks the design methods that can combine perfectly Kirgiz patterns with design to guide the practice of ethnic designs, thus it can promote the development of minority culture and the arts.
\end{abstract}

Due to the remote geographical location, the art of Kirgiz in Akqi County of Kirgiz state in Xinjiang has been seldom affected by the outside world during the thousands of years. It maintains the combination of primitive simplicity and nature. Their art is in harmony with nature and life. As the image carrier of social and folk culture of Kirgiz, the ethnic decoration patterns of Kirgiz vividly express their abundant and colorful lives, and reflect their aesthetic ideas and emotions. It is not only a part of the folk life and the customs of the Kirgiz, but also the precious art of Kirgiz living in the southern range of Snow Mountain.

The redesign of the decorative patterns of Kirgiz refers to reconsidering and positioning users and modeling, and application methods of the existing decorative patterns so as to endow them with fashionable appearance, play a role of modern decoration, adapt to the existing life-style, and satisfy the rigid demands proposed by the tourism of Kirgiz on the redesign of their decorative patterns.

Decorative pattern of Kirgiz is not only enlightened by the contemporary new life and new cultural patterns, but also affected by the inseparable tradition. Moreover, it also needs to inherit the excellent gene of national cultural spirit. Only in this way can the decorative pattern of Kirgiz establish new national characters with great vitality under the background of new era.

1. From it, ingenious using

The establishment of innovation and application mode of the decorative pattern of Kirgiz is based on its complete collection and summarization ,sorted generalization of its drawing so as to draw the structure of the visual representation of the patterns. Afterwards, the patterns are deeply explored from points to surfaces so as to understand its deeply cultural connotation. The truly revolutionary creation can be completed by such an analytical method, rather than simply copying and duplicating the patterns. In Figure 1-1, the author takes the wall hangings in decorative pattern of Kirgiz as an example to analyze the extracted original elements. The decorative patterns in wall hangings of Kirgiz are generally composed of three-layer structures of central pattern, edging, and vertical curtain. The central pattern is mainly made up of Ram's horn patterns, cross patterns, eagle patterns and plant pattern. The animal patterns are relatively common, and they represent strength and abundance. The edges of the central pattern are mostly decorated with bird claw patterns, which symbolize freedom and vigorousness. The outermost layer is decorated by $\mathrm{S}$ pattern, mountain pattern, and cattle corn pattern supplemented by vertical curtains and tassels. The center patterns are suitable patterns and the square continuous pattern, while the outer decorative patterns are two-dimension series patterns. 


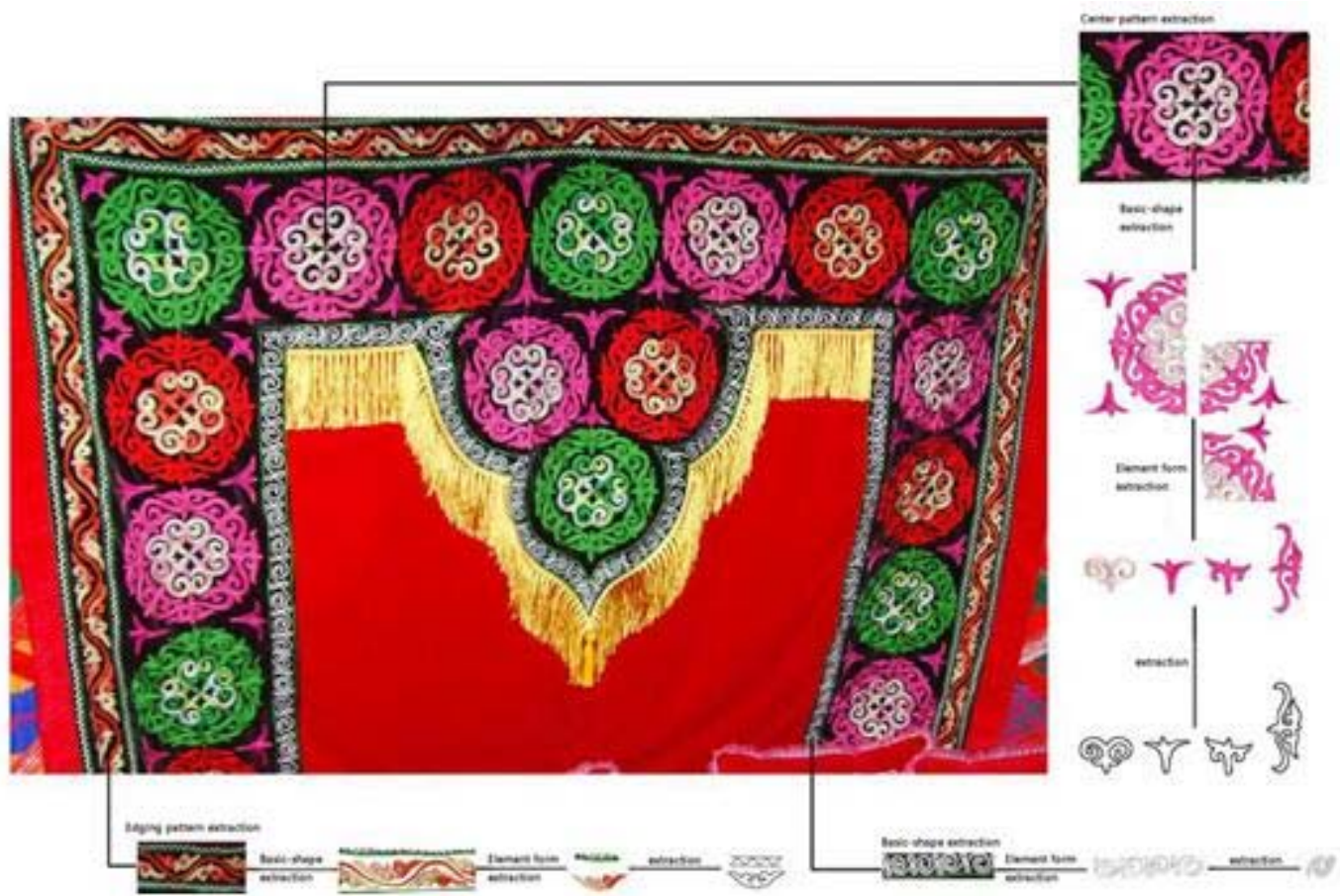

Figure 1-1 The original element extraction in wall hangings of Kirgiz

Combined with previous research, the decorative design pattern of Kirgiz can be approximately divided into six categories of fierce animals, plants, natural phenomena, weapons tools, geometric graphics, and life appliances according to the morphological analysis. Representative elements of the six categories of decorative patterns are separated from the complex tissue by extracting unit pattern so as to generate new graphical representation forms through subsequent transformation. This will become the main source for the author to extract the original elements of decorative patterns of Kirgiz. The classification, sources and legend of the material are summarized in Table $1-2$.

Table 1-2 Statement of information classification and extraction elements

\begin{tabular}{|c|c|c|c|}
\hline Classification & Item & Source & Legend \\
\hline fierce animals & $\begin{array}{l}\text { Deer pattern, horse pattern, } \\
\text { sheep pattern, eagle pattern, } \\
\text { snow leopard pattern, } \\
\text { camel pattern, ram's horn } \\
\text { pattern, livestock bone } \\
\text { pattern, livestock hoof } \\
\text { pattern, and livestock } \\
\text { kidney pattern,etc. }\end{array}$ & $\begin{array}{lr}\text { Cliff } & \text { painting, } \\
\text { felted } & \text { texture, } \\
\text { knitting, } & \\
\text { embroidery, wood } \\
\text { carvings, } \\
\text { break wind, } \\
\text { drawing, } \\
\text { works, profered } \\
\text { painting } \\
\text { photograph } \\
\text { by the author. }\end{array}$ & 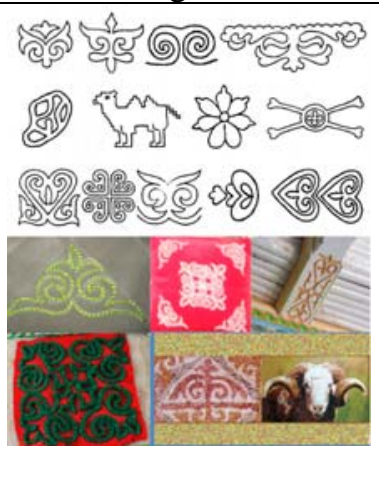 \\
\hline plant & $\begin{array}{l}\text { Grape pattern, fig pattern, } \\
\text { Almonds pattern, lotus } \\
\text { pattern, lotus throne } \\
\text { pattern, honeysuckle } \\
\text { pattern, Xinjiang Fritillaria } \\
\text { thunbergli pattern, and } \\
\text { pomegranate pattern, etc. }\end{array}$ & $\begin{array}{lr}\text { Felted } & \text { texture, } \\
\text { knitting, } & \\
\text { embroidery, } \\
\text { professional } \\
\text { painting books, } \\
\text { photograph taken } \\
\text { by the author, } \\
\text { private houses, } \\
\text { periodicals and } \\
\text { magazines, etc. }\end{array}$ & 1980 \\
\hline
\end{tabular}




\begin{tabular}{|c|c|c|c|}
\hline $\begin{array}{l}\text { natural } \\
\text { phenomena }\end{array}$ & $\begin{array}{l}\text { Sun pattern, moon pattern, } \\
\text { star pattern, the mountains } \\
\text { and rivers pattern, river } \\
\text { pattern, cloud pattern, fire } \\
\text { line, and lightning pattern, } \\
\text { etc. }\end{array}$ & $\begin{array}{l}\text { Embroidery, } \\
\text { professional } \\
\text { painting books }\end{array}$ & 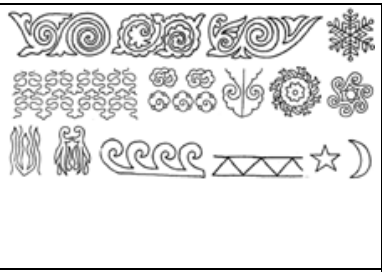 \\
\hline weapons tools & $\begin{array}{l}\text { Knife pattern, gun pattern, } \\
\text { sword pattern, halberd } \\
\text { pattern, and spear pattern }\end{array}$ & $\begin{array}{lr}\text { professional } \\
\text { painting } & \text { books, } \\
\text { photograph } & \text { taken } \\
\text { by the author, } \\
\text { museum }\end{array}$ & 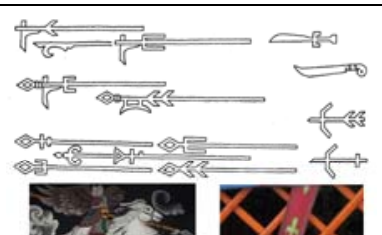 \\
\hline $\begin{array}{l}\text { geometric } \\
\text { graphics }\end{array}$ & $\begin{array}{lr}\text { Triangle } & \text { pattern, } \\
\text { honeycomb } & \text { pattern, } \\
\text { hexagonal pattern, square } \\
\text { pattern, cross pattern, } \\
\text { rectangular } & \text { pattern, } \\
\text { octagonal pattern, arrow } \\
\text { pattern, sawtooth pattern, } \\
\text { rhombus pattern, circle } \\
\text { pattern, S pattern, svastika } \\
\text { pattern, ancient coins } \\
\text { pattern, straight line } \\
\text { pattern, curve pattern, etc. }\end{array}$ & $\begin{array}{l}\text { Felted texture, } \\
\text { knitting, } \\
\text { embroidery, wood } \\
\text { carvings, wind } \\
\text { break wall, colored } \\
\text { drawing, inlay } \\
\text { works, professional } \\
\text { painting books, } \\
\text { photograph taken } \\
\text { by the author. }\end{array}$ & 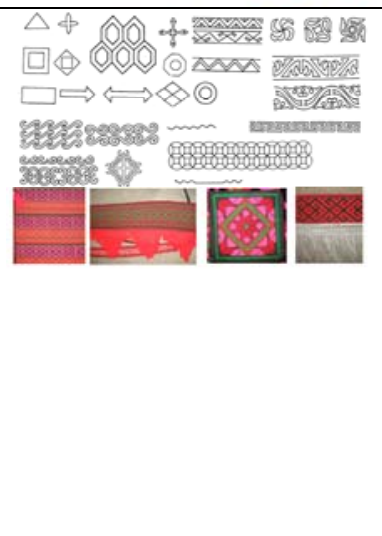 \\
\hline life appliances & $\begin{array}{l}\text { Pot pattern, bottle pattern, } \\
\text { ancient clock pattern, bell } \\
\text { pattern, and jar pttern }\end{array}$ & $\begin{array}{l}\text { Professional } \\
\text { painting books }\end{array}$ & 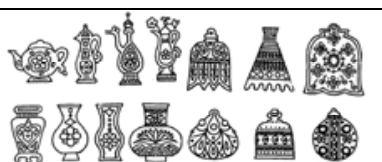 \\
\hline
\end{tabular}

2. Indigo blue is extract from the indigo plant, but is bluer than the plant it comes from.

The natural world is constantly changing. Similarly, the redesign of decorative patterns of Kirgiz should never be invariable. It is originated from the original graphics, which is redesigned to create colorful art forms and artistic style, and integrate modern culture, modern aesthetic consciousness and personal wisdom into the creation. In this way, it is more excellent than the original pattern in meeting the current demands.

(1)Variant modification of basic pattern

Secondary abstract: The most typical and significative elements need to be extracted through concise method so as to transform and change the decorative patterns of Kirgiz On this basis, the pattern will be exaggerated, decorated and regrouped. According to the method utilized to extract the original elements in the wall hanging shown in Figure 1-1, the extracted element are added and subtracted to realize the artistic treatment of points, lines, and surfaces of original elements and achieve the purpose of "redesign". Affected by abstractionism and modernism, modern decoration manifests the logic beauty and order beauty. Therefore, abstract geometric patterns are widely used. This is also one of the considerations for the author to redesign the decorative patterns of Kirgiz By means of the transformation treatment of decorativeness of simple patterns and simplification of complex patterns, the decorative patterns of Kirgiz will present modern aesthetic perception and demonstrate the value of contemporary design.

Reproductive imagination: For the redesign of the decorative pattern of Kirgiz, what the original elements map in the mind is an inspiration point of art creation. It is a relevant pattern caused by a unit shape, and the induced imagination digressing from the infinite imagination of original form. Through the modern formal rules and aesthetic ideas, the new patterns are integrated and created.

Scatter and remodeling: The variable parts of the elements in the decorative pattern of Kirgiz are partially extracted by scattering the original pattern, which are extended, changed and transformed through modern art form. Scatter and remodeling are the most important method for redesigning the decorative pattern of Kirgiz The original patterns are separated and split without specific restriction. 
Afterwards, the extracted most representative elements in the decorative pattern of Kirgiz are realigned and combined according to certain rules so as to derive new patterns. The unit hoof patterns and eagle patterns in the decorative pattern of Kirgiz shown in Figure 3-2 are representative. The characteristic parts are recombined, and the exquisite parts and angles are selected to retain the most representative features for remodeling and obtain new decorative patterns after redesign.
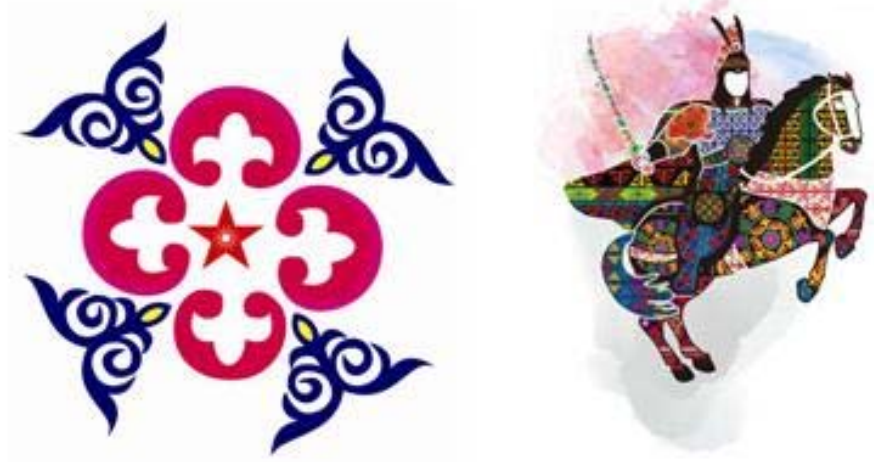

Figure 2-1 Scatter and remodeling of Kirgiz's decorative patterns

\section{Color inheritance and variation of classic patterns}

Color inheritance refers to inheriting and continuing. In specific redesign, color matching method based on the classic decorative patterns of Kirgiz can achieve excellent inheritance effects. Color variation refers to variation and originality. It breaks the limitation of the traditional color system, and appropriately changes the local color. Combined with the modern color rules, the classic decoration designs take on an altogether new aspect. The extraction and integration of the color in the decorative patterns of Kirgiz are of great importance. Their color use preference are refined so as to deeply study the belief represented in the color and determine the proportion and effects of the original colors in redesign. Only in this way can the original national features and life charms of the decorative patterns of Kirgiz in the application of modern design.

(1) Color inheritance of traditionally classic decorative patterns of Kirgiz

The color representation patterns in decorative patterns of Kirgiz generally are bright-colored, striking, lucid, and lively. The decorative patterns of Kirgiz are mainly red, green, blue, yellow, or purplish red so as to generate splendid and vivid color. Furthermore, the color matching with high purity and clarity seems to be contradictory. However, it contains the characteristics of artistic aesthetics and the entire image is riotous with color. Furthermore, it presents deep, moderate and light-colored de-halo treatment, and the gradation will be abundant. The author takes the wall hanging as the example to extract its color. In Figure 2-3, the colors in decorative patterns of Kirgiz are extracted to carry out the chromatographic analysis. This is the main method to extract color in this paper, which provides theoretical basis and color techniques for the color matching of subsequent redesign.
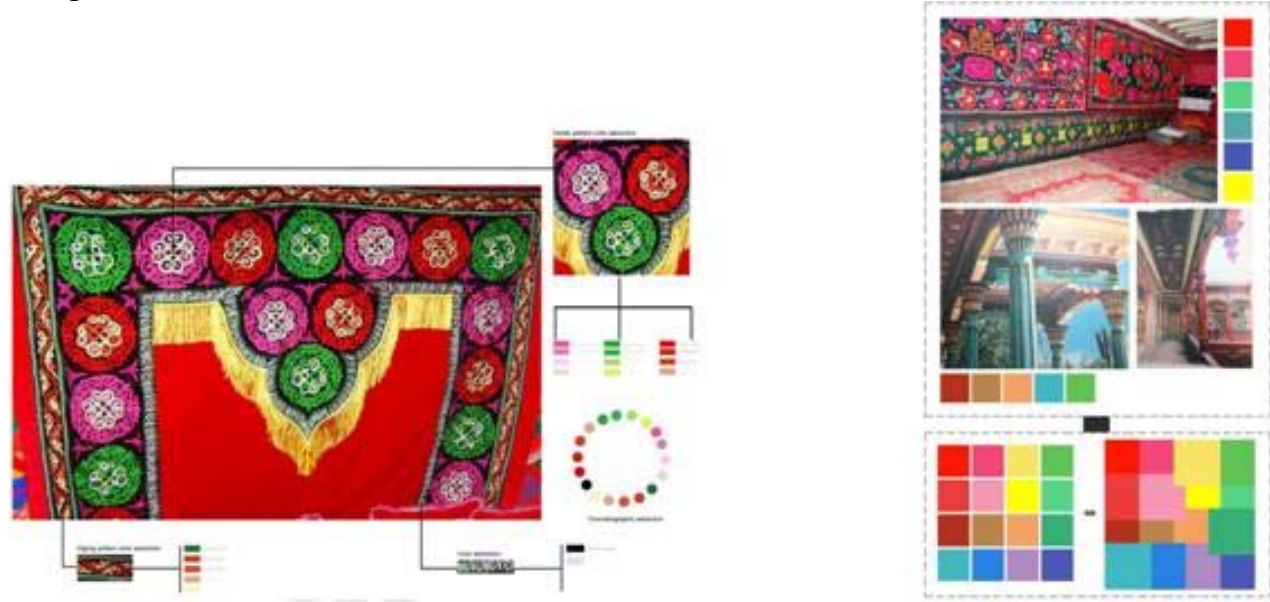

Figure 2-2 Extraction of color in wall hanging of Kirgiz

Figure 2-3 Extraction of color preference in decorative patterns of Kirgiz 
Table 2-4 Analysis and comparison of commonest colors in decorative patterns of Kirgiz

\begin{tabular}{|c|c|c|c|c|c|c|}
\hline Black & White & Red & Green & Blue & Yellow & Purple \\
\hline$\star \star \star$ & $\star \star \star \star \star \star え$ & 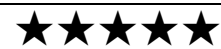 & $\star \star \star \star \star え$ & 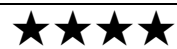 & 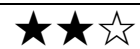 & $\star \Sigma$ \\
\hline
\end{tabular}

According to the analysis of commonest colors in decorative patterns of Kirgiz shown in Figure 2-3 and Table 2-4, it can be seen that the five colors of black, white, red, blue, green, particularly black, white, red, blue, are the colors commonly used by Kirgiz, which represent the vast and holy connotation. Black, "Gala" in Kirgiz language, represents not only color, but also geographic orientation. It symbolizes black landscapes with vast and holy connotations. Blue, "kuoke" in Kirgiz language, is the color of sky. Therefore, it is regarded as a sacred color. White, "ake" in Kirgiz language, represents the clear and bright moon. The word containing "Ake" generally represents respect. Red, "Hzier" in Kirgiz language, represents the fiery sun, which is the color of fire. It contains the custom of primitive religion belief and ethnic characteristics with strong enthusiasm.

(2) Color variation of traditionally decorative patterns of Kirgiz

The color variation of decorative patterns of Kirgiz is mainly reflected in two respects, namely the applications of intuitionistic presentation and deeply symbolic images. Combined with the modern aesthetic appreciation, the original color style is retained. Through the improvement of the constitution characteristics of color itself and the reorganization of the relationship of colors, a new color vision language is generated so as to adapt to meet the demands of the development of modern society. In this way, the redesign of the decorative patterns of Kirgiz can realize sustainable development. The complementary color contrast, multiple hues contrast, and strong shading effect in aspect of visual representation are what pursued in the vision of the modern design. The decorative patterns of Kirgiz generally take black background as the patterns. The background of single color can make the patterns more unified and harmonious. In integration variations in the color redesign uses the single line to draw the edges, which plays the role of spacing and buffering colors. This paper expects to use the visual representation of the color in the color of packaging design. The alternations of colors are integrations of colors. The superimposition, repetition and continuation of colors achieve the effects of color harmony, contrast and unity. The colors generally have a specially symbolic meaning in the aspect of deep symbolic image. They are closely related to the natural living environment and the original supply of life. Actually, the colors are the perfect portrayal of their love and advocating for nature.

The author proposed the redesign of the decorative patterns of Kirgiz based on the consideration on their market value, aesthetic value and emotional value. Ductility and variability of redesign enable decorative patterns of Kirgiz to realize better metamorphosis. The extension of sustainability can't be completed through individual design, but multiple scatters and reconstructions. The improvement and redesign of the secondary abstract are the performance of continuous appreciation.

\section{Summary}

In the phenomenon of today's art return, the redesign of decorative patterns of Kirgiz is a good opportunity to promote its transformation to modern design. The inspiration and color in the decorative patterns of Kirgiz can be absorbed and extract to generate the design works containing new contents forms that hasn't been separated from folk-custom. In this way, the redesign of decorative patterns could run over with contemporary values of originate charm and modern aesthetic appreciation so as to convey the concept of cultural artistic conception and appeal design. Furthermore, the audience can appreciate the cultural heritage of color in the artistic conception of design elaborately created by the designers, associate with the artistic conception, and feel the charm of nomadic people.

\section{References}

[1] Maimaitiaishan • tuohudali. Chinese Kirgiz [M]. Volksverlag Xinjiang, 2006,5. 
[2] Li Binbin. Design Psychology [M]. China Light Industry Press, 2005,8.

[3] The Xinjiang Uygur Autonomous Region Foreign Cultural Exchange Association. Kirgiz Folk Culture [M]. Xinjiang Art Photography Publishing House, Xinjiang Electronic Audio and Video Publishing House, 2006,12.

[4] Zhong Fumin. The Symbol of Auspicious Patterns Research in China [M]. China Social Sciences Publishing House,2009.

[5] Zhao Maosheng. Decorative patterns [M]. China Academy of Fine Arts Publishing House, 1999.

[6] Li Xiaobing. Xinjiang in China. Design of Turpan Folk Decorative Art [M],1997. 